\title{
Explorations into Becoming New, Radical, and Quite Possibly Dangerously Progressive within an Aotearoa New Zealand Context
}

\section{Nicola Dunham ${ }^{1}{ }^{*}$, Hazel Owen ${ }^{2}$ and Yo Heta-Lensen ${ }^{1}$}

1 Te Kura Whanui, Unitec Institute of Technology, Auckland, 1025, Aotearoa, New Zealand; E-Mail: yheta-lensen@unitec.ac.nz

2 Ethos Consultancy NZ, Auckland, 1142, Aotearoa, New Zealand; E-Mail: info@ethosconsultancynz.com

* Author to whom correspondence should be addressed; E-Mail: ndunham@unitec.ac.nz; Tel.: +64-9-815-4321.

Academic Editor: John Blewitt

Received: 28 January 2015 / Accepted: 26 March 2015 / Published: 9 April 2015

\begin{abstract}
This paper draws on an initiative where we experienced being new, radical, and, from some viewpoints, dangerously progressive at Unitec - a Polytechnic/Institute of Technology in Aotearoa, New Zealand. The initiative was driven by a need to improve student experiences of interdisciplinary learning and teaching, and to develop a common semester for students transitioning to a bachelor degree programme, as well as a new suite of interdisciplinary qualifications at postgraduate level. This discussion paper is situated within a self-study paradigm befitting educational contexts, by drawing on the reflective narratives of three participants who held a range of different roles - and, hence, perspectives within the change process. Interpretations and implications are discussed using the lens of the Inclusive Framework, to illustrate personal, professional, and political elements. Our overall aim is to add to current understandings of change within the higher education sector. However, this is a study of our own experiences and we are not making claims that we are in the possession of "truth", but, rather, we seek to identify aspects that may have relevance in other contexts. We conclude that navigating the next phase of transformative change in our context will involve seeking resolutions to key emerging questions. This includes exploring notions of
\end{abstract}


multiple innovators, creating agile development environments in education and exploring the concept of time as multifaceted.

Keywords: Aotearoa New Zealand; reflective narratives; Inclusive Framework; transformative change

\section{Introduction}

In simplistic terms, there are two types of change in education: cyclical and transformative [1]. Cyclical change is ongoing [2], and institutions often initiate it, or respond to it as it happens, occasionally returning to the state they were in before [3]. In contrast, transformative change is holistic, disruptive, often uncomfortable, collaborative, happens at all levels, and is irreversible [4]. In other words, once an institution or community has undergone transformative change, it will not be able to return to the way it was before. However, one issue is that what is actually cyclical change (appears "new"), is often described as transformative ("progressive").

Tension is becoming apparent between existing procedures, systems and processes in education and a need to re-think what education is and how people learn. This could be why there is a sense that confidence in formal education is declining, alongside a growing interest in radical solutions, such as non-formal education [5]. Furthermore, the notion that formal education prepares you for the rest of your life is fundamentally flawed. Rather, education should be designed to empower you to develop the lifelong learning skills that will equip you to be responsive to change as it happens, and to prepare for future change. The gap appears to be widening between "information" (the word is used advisedly) and skills taught, and the living and working environments being prepared for. As such, rather than continuing to do the same things slightly differently, there is a need in education for a greater appetite for innovation, as well as an understanding of the change innovation catalyses.

In this paper we will be discussing our experiences of the implementation of a large flipped and blended-learning project at Unitec, a tertiary institution in Aotearoa, New Zealand. Tertiary education in Aotearoa New Zealand covers all post-secondary education including the delivery of programmes from certificate to Ph.D. level [6], and is akin to the term Higher Education in other countries. While a traditional paper may begin within a review of the literature we will instead begin with describing the context in which the change process took place.

Our discussion is based on the personal reflections of three participants, who had a range of different roles - and hence perspectives - within the change process. The interpretations of these three reflective narratives will be discussed, using the lens of the Inclusive Framework to frame the personal, professional and political elements of the reflections [2]. Our overall aim of sharing these experiences is to add to current understandings of the challenges of being new, radical and progressive within the higher education sector. The topics covered in the paper are wide-ranging and touched on only lightly, in part to highlight the wide range of factors that shape our experience of change. In future papers we plan to explore areas, such as identify and "becoming", in greater depth.

We hope that this approach will, in itself, not prove too radical for you-our audience. 


\section{Stepping Out of the Mould}

This paper does not fall into the category of a research paper per se. We are aiming to draw on the principles of phenomenology to explore "lived experience" from the perspectives of the contextually situated people involved [7]. Reflective accounts are a means by which lived experiences can be attributed meaning. Schutz [8] (p. 69) writes that "it is misleading to argue that experiences have meaning. Meaning does not lie in the experience. Rather, those experiences are meaningful which are grasped reflectively". Therefore, in the construction of this paper we have taken a somewhat alternative approach by weaving reflective accounts into the main discussion rather than following a more traditional data presentation formula. Through this study we are not making claims that we are in the possession of "truth" [9]. Rather, we are approaching this experience of knowing as one of potential transformation, in that our own state of being, and, therefore, doing, is affected and changed by the new knowledge we encounter through this process [10].

The reflective accounts informing this paper are placed within a self-study paradigm befitting educational contexts [1]. Frameworks for self-study include consideration of principles of personal situated inquiry and critical collaborative inquiry [11], which are evident within our exploration of the impact of change at Unitec. The variety of perspectives add richness to the learning by sharing the knowledge gained, and as such are in keeping with the principles of self-study approaches [11].

As three participants in the study (also the authors of this paper), we have worked together closely on the project in question; two of us since September 2013, and all three since February 2014. In this sense we have incorporated the principle of personal situated inquiry into our reflective accounts [11]. We each separately wrote reflections about our experiences, from a stance of identity and integrity, doing "something [that is] alien to the academic culture", describing our "inner lives — risky stuff in a profession that fears the personal and seeks safety in the technical, the distant and the abstract" [12] (p. 12). The researchers then analysed each of the reflections, independently identifying key emerging categories, as well as codes drawn from the conceptual framework provided by the Inclusive Framework [2]. A synthesis of codes and themes from the three reflections were then collated and form the heart of this paper. The use of independent analysis, along with cross analysis, is in keeping with the principles of critical collaborative inquiry, helping to ensure a transparent and systematic research process [11].

As participants we have performed several key roles in the project, and are therefore able to provide different perspectives and insights into motivations, challenges, and professional development needs that may help inform innovation in education. Given that the project is ongoing, to help preserve some semblance of anonymity, quotes are attributed to participant 1,2 , or 3 , or the person's role, where it is necessary for clarity.

\section{Situating the Change Process}

The change process at Unitec was driven by initiatives to improve student experiences of learning and teaching; enhance interdisciplinary education through shared and common courses across disciplines; introduce a common semester for all first year students transitioning to a bachelor degree programme; and develop a new suite of interdisciplinary qualifications at postgraduate level within the Health Science 
faculty. While this, in itself, is not new or radical in a more global tertiary education context, it was certainly both for Unitec in the context of Aotearoa, New Zealand.

\section{Blending and Flipping}

It has been suggested that blended learning is "a blending of campus and online educational experiences for the express purpose of enhancing the quality of the learning experience" [13] (p. 5). However, this definition neither includes information about how to enhance the learning experience, nor advises how campus and online experiences are to be blended [14]. Heinze and Proctor [15], in contrast, classify blended learning as "learning that is facilitated by the effective combination of different modes of delivery, models of teaching and styles of learning, and founded on transparent communication amongst all parties involved with a course". In the Unitec context, the notion of "blended" aligned closely with the Heinze and Proctor view, whereby the conceptualisation, design, development, and facilitation used the affordances of technology to enhance collaborative processes (synchronous and asynchronous), project discussions, professional development, course design, and the facilitation of sessions with students.

Although many definitions of flipped learning focus on reversing what happens "in" and "out" of the classroom, "at its core, the flip involves shifting the focus from the facilitator to the learners", in part by "inverting the design of the course so students engage in activities, apply concepts, and focus on higherlevel learning outcomes" [16] (n.p.). Therefore, the course design drew on the principle of learning being an active process where students engage with learning activities, materials and resources prior to attending facilitated synchronous sessions (either face-to-face or in a webinar). Prior learning could then be extended by facilitators and peers - especially important in courses where students may be working and have years of experience. Interdisciplinary learning was, in this context, about not siloing students into discipline-specific learning. Instead students were encouraged to explore issues from the perspectives of multiple practice and discipline perspectives.

One caveat we were cognisant of was that technology by itself does nothing to enhance learning and teaching; as such sound pedagogical theory and eLearning principles needed to be the driving forces. Additionally, at a practical level, for blended, flipped learning to be effective, several changes needed to take place in the attitudes and professional practices of the educators involved [17]. In other words, we needed to design, develop and implement a blended, flipped approach to interdisciplinary learning that would offer opportunities for an active and applied learning experiences. These opportunities, it was hoped, would support students to develop the skills to be "self directed, co-constructive, collaborative, lifelong learners" (Participant 3). In addition, the approach included quite radical changes in delivery, management, and processing.

\section{A New Centre for Interdisciplinary Scholarship}

As part of the change process a new Centre for Interdisciplinary Scholarship was established which, in May 2014, became known as Te Kura Whānui. "Kura" (a te reo Māori word that literally means school) represented the notion of growth, learning and development. "Whānui" was chosen as indicative of wider connections and something that is responsive to diversity and interconnectedness. Figure 1 [18], depicts the basic structure of Te Kura Whānui in terms of how it is situated within the institution. 


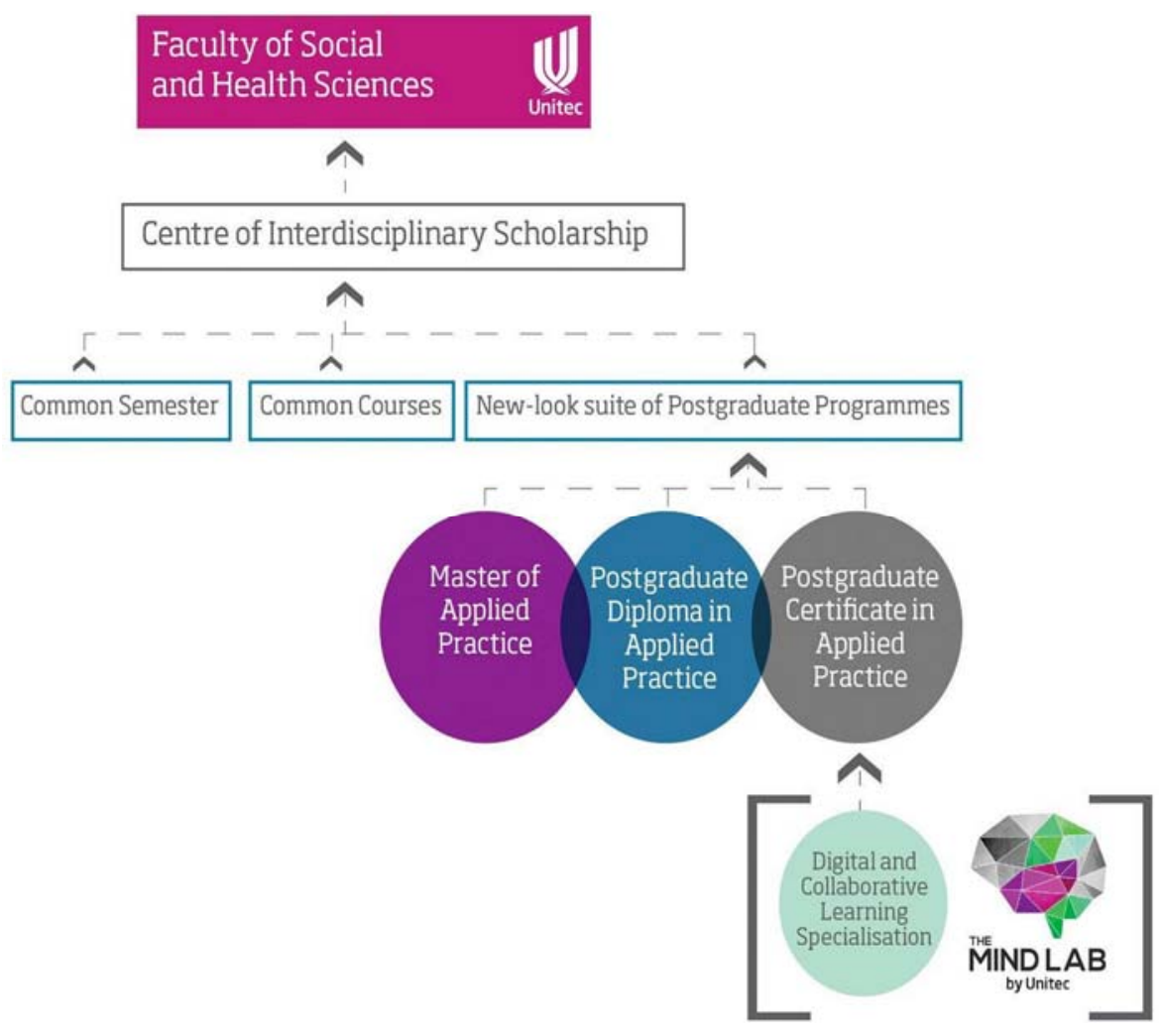

Figure 1. Structure of Te Kura Whānui [18].

Being centrally located in the Faculty of Social and Health Sciences, the centre spans all faculty-delivered undergraduate programmes of study. The centre is also the location for the new Master of Applied Practice and the Professional Doctorate, which encompass all postgraduate study from across the institution.

\section{The Staff}

The staff that comprise Te Kura Whānui come from a range of discipline areas from the institution. Some staff are full time members of the centre which means all of their responsibilities lie within the centre. Others hold proportional roles which are split between the centre and other departments. In all cases working within Te Kura Whānui has resulted in significant changes in terms of work. Roles changed and evolved as the centre grew at times adding to the need to be responsive and flexible as the change process dictated. The roles held by any one staff member could include:

- Course development: Subject matter expert, Course writer, Curriculum editor

- Course delivery: Course leader, Course facilitator

- eDevelopment: eLearning designer and developer

- Consultancy: eLearning project manager, eLearning team leader

- Cultural context: Kaiarahi supporting and informing the blended learning from a Kaupapa Māori perspective.

Te Kura Whānui took responsibility for the development of courses, and the support of the facilitators who would provide interdisciplinary education and a common semester. The course design and development process was perceived by some staff as (dangerously) progressive as it shifted from being the sole 
responsibility of individual lecturers isolated in their departmental programmes, to becoming a team-based, collaborative and transparent approach at all levels: from writing and design, to facilitation of the courses. This new institutional approach to course design led to the re-framing of roles, for both lecturer (to facilitator), eLearning designer (to mentor and guide), and student (to active learner), often enabled by the affordances of online spaces, tools and critical use of existing web resources, as essential components of a re-conceptualised approach to learning and teaching.

\section{Teaching Elephants to Tip-Toe: Change in Education}

Within New Zealand, studies conducted into innovative curriculum and teaching illustrate that innovations tend to occur in "pockets" [19], and that "long-term, system-wide change is extremely difficult. It requires a culture shift: a new environment in which the majority of teachers think in new ways, develop new skills and have new understandings of themselves as professionals" [20] (p. 43).

The pace, nature and demands of change in the work of the educator are currently extremely challenging in part due to social, technological and political change [21], driven by policy makers at state and local levels [19]. As a result, many educators are experiencing tension between an awareness of a world of changing paradigms and a desire to maintain an academic professional and personal identity that has been long in the making. Such tension was encapsulated in the reflective narrative from Participant 1 who "was ... hearing deep down was that the time was ripe for change; change which despite some people's sense of utter surprise was an issue that had been on the institutional radar for a number of years". She goes on to say that: "An important point of learning for me at this time was that my place and space within the institution was shifting and that I needed to approach this new ground with insight, consideration and also a degree of caution".

\section{Interpretive Framework: A Lens for Change}

Life experiences shape an educator's beliefs about learning and teaching. In addition, their professional "knowledge" can be seen as experiential and set in particular domains and contexts [22], some of which may also be personal [23]. Therefore, at the heart of the Inclusive Framework is the development of professional identity and practices — something that is best understood as a process of becoming [24].

\section{Personal}

The personal dimension is powerful in both learning and teaching. It is the who-the essence-in the evolving self [2]. If viewed through an education lens, it encapsulates the shift, using critical reflection, from being to becoming, to a state where the educator has sufficient confidence to embrace uncertainty, to move from the known to the unknown, and to develop the confidence to change their own and others' ideas.

Adding to the dimensions of the inclusive framework, the Diffusion of Innovation Adoption Curve illustrates that a few individuals will always be fascinated by "the new"- the innovators [25]. This theory suggests that once the potential of a new initiative or technology is recognised others become interested (the early adopters). Each subsequent category of adopters (early majority, late majority, and late mass), building on the early results of the innovation, acts to influence the next category. A key issue becomes 
apparent once the innovators and early adopters are on board, the project is underway, and the phenomenon of the "chasm" is encountered [26], whereby momentum is required to reach the "tipping point" [27], and the people in the other categories start to adopt the idea. Unless reasons are compelling, the adoption process can become stalled in the "chasm" [28].

\subsection{Mindsets}

Analysis of the reflective narratives identifies that the cause of change at Unitec was the access to resources - in this case people — who have the mindset associated with innovators. The innovators developing the concepts also required innovators at the level of practical application who could see the ideas through to fruition, and move ideology into practice (Figure 2). Two of the participants in this project appeared to be innovators, and one an early adopter-factors that seemed to be inseparable from the personal dimension (the "who"), which came through strongly in all three reflections. A question raised by this is whether there are actually different kinds of innovators, and what the implications of this are.

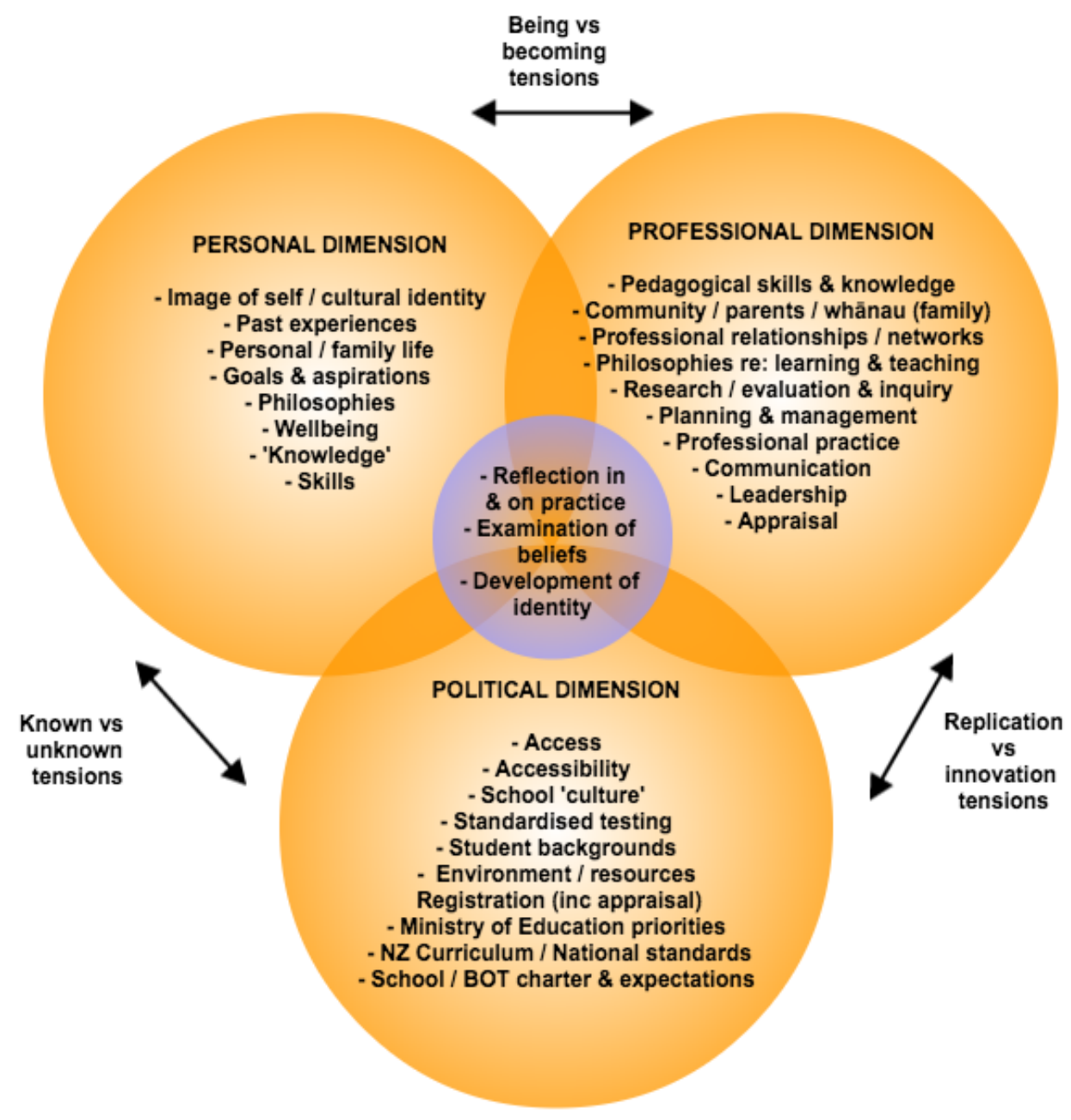

Figure 2. Inclusive Framework ([2], adapted from the Teacher Thinking Framework, [29]).

In keeping with the personal dimension of the Inclusive Framework, Mezirow applies the term "subjective reframing" when talking about how constructions of reality are transformed and when an individual's perspective is not in harmony with their experience, explaining that "the most personally 
significant transformations involve a critique of premises regarding the world and one's self" [30] (p. 22). In all three reflections there was a sense of curiosity, self-reflection, openness to progress, a sense of self in the face of challenge, and, in one participant's case, a strong sense of cultural identity. All of these influenced perceptions of themselves in their roles. Participant 1 identified herself as having "a tendency to get itchy feet and a bit of a change magnet", who was ready to "be part of something bigger". In the face of challenges she described herself as "a terrier in nature, I clung on and dug in". Likewise, Participant 2, saw herself "intrigued" about the proposed changes, but admitted "to almost pulling my hair out", at times of inevitable stress, which helped highlight for her the "complexity of change and change management". In contrast, Participant 3 was more ambivalent about change, and saw this particular project, for someone who identifies strongly as Māori, as something where "the risk is unknown and the stakes are quite high". Her approach to working with challenges was, she realised, "rhizomatic", enabling her to employ "non-hierarchical approaches... [that] allow for multiple entry and exit points".

While all three acknowledged multiple sources of stress, it appeared that their willingness to take risks, a well-developed resilience, and a creative attitude to problem-solving, helped them overcome difficulties, and relish the change to the point where Participant 1 indicated "I was really feeling a sense of flying, of freshness and a chance to give things a go". Without this combination of personal disposition-a willingness to "become"-it is unlikely that the participants would have been involved in the initial stages of change.

One aspect that appears to be quite hopeful is that some staff have been convinced by the results of the innovators and early adopters, and are beginning to form the promise of an early majority of course writers and facilitators [31]. Participant 1 highlights that the road to positive results has not been smooth, whereby in the phase 1 roll-out to students in 1 Semester 2014 "gaps in existing orientation systems emerged which at the time left both students and the teaching team exposed: providing an ideal environment for doubt, despair and scepticism to run riot". Toward the second half of the semester "students...were showing signs of engaging and succeeding. The final sign of triumph coming with our innovative integrated assessment. At last we could see the learning that had occurred and just what the students could achieve". In addition, Participant 2 explained that she "felt really positive that we were developing courses that would be as accessible as we could make them, would be culturally responsive, would still "look and feel" different to the usual blended learning experience". At this point the three participants seem to have sufficient confidence to embrace uncertainty, to continue to move from the known to the unknown, and further develop their own ideas.

\subsection{Tensions between Agency and Accountability}

The impact of education systems on individual teacher agency often results in an uneasy combination of regulation and accountability, and a desire (and sometimes a requirement) to be innovative. Agency is thereby bound by parameters that can feel stifling or dangerously progressive where, there is a sense of possibly being "found wanting"- something that Madeline Campbell captures when she suggests that "plunging headlong into something apparently "innovative" can leave a teacher plagued with doubt, and nervous about the risk of change" [32] (n.p.). This can be exacerbated when, as Participant 1 reflected, the educator is made to feel that by becoming involved in change they have "stepped over to the 'dark 
side", or where, as Participant 3 shares, a "conversation that occurred quite by chance in the middle of the mall" with a student leaves her questioning her own shifting beliefs about learning.

All three participants have faced tensions between an eagerness to engage and apply themselves to a high standard, and the demands of personal life and family. All, therefore, have had to work on balancing an eagerness to be involved in a demanding project, with a desire to meet a range of other professional aspirations (two, for example, are studying for their doctorates), while also ensuring their own emotional and physical well-being. The complexity of these factors may help explain why some educators feel exhausted, and Participant 2 observed that her colleagues were "working in the evenings and at the weekends [which] means they are spending less time with friends and family" just to "keep up" with the demands of change. These, sometimes contradictory, drivers can leave people feeling risk averse and overwhelmed. A key question being: how can an institution meet the heavy demands of transformational change, working with innovators and early adopters, without them burning out?

\subsection{Collaboration and Trust}

Participation and non-participation is, in part, behaviour that is influenced by affective factors such as identity, belonging, collaboration and trust. These factors need to be flexible enough to accommodate, for instance, "Kaupapa Māori [which] takes a co-constructivist approach to knowledge...in that meaning is collectively found and knowledge is shared" (Participant 3). Such affective factors contribute to what Dron [33] refers to as "Social Velcro"- the elements that help a group to form and "stick" together in a way that enables them to work together effectively, but then to "unstick and reassemble" when necessary. The social structures that establish are underpinned by agreements about interactions, processes, norms, and rules - although these too are in a constant state of flux, being re-negotiated, evaluated and altered [19].

Participant 1 identified that the "whole endeavour has been highly collaborative: a less than usual practice within academic course development". She nevertheless acknowledges that it "has not been a given, rather more a hard earned state of being". Participant 2 likewise indicated the "need for a team to be built not only on skills and experience, but also on relationships, complementary (but not necessarily the same...challenges are good, and echo-chambers can be stifling) beliefs about learning and teaching, and an openness to true collaboration". The benefits of such an approach included:

- an enjoyment of co-constructing knowledge - "there is a dynamic sharing and interweaving of work experience, learning, and knowledge, that creates the connections between our 'knowledge' to form something 'new' - something I couldn't have come up with on my own" (Participant 2);

- enhanced peer support-Participant 1 writes "I had Participant 2 supporting me" and Participant 2 explains that "I have been inspired and supported by Participant 3";

- trust - "I thrive on this! I am constantly learning and being stretched, personally and professionally. It's a big highlight for me" (Participant 2);

- a sense of belonging with "likeminded colleagues" (Participant 1);

- a sense of belonging - "I remain genuinely excited by working with the colleagues (some of whom have become good friends)" (Participant 2). 
To a certain extent the factors that we have unpacked and discussed in this section are intertwined with professional and political aspects, but it is personal dispositions, as well as support from the group involved in the change, which influenced how the participants responded to adversity, and ultimately made the decision to continue with their uncomfortable journey of becoming.

\section{Professional}

Some educators subscribe to a 20th century view of learning and knowledge where they see their role as supporting "students to passively acquire and reproduce existing knowledge" [34] (p. 6). The paradigm shift required for educators to instead help students "actively interact with knowledge: to... understand, critique, manipulate, create and transform it" [34] (p. 6), is substantial. It requires them to reconsider their identity as an educator - to re-situate their beliefs, knowledge, learning and professional practice [35].

The professional dimension in this framework considers the how of learning and teaching through reflection in and on action [2]. Bolstad [36] (p. 15) has shown that practitioners who are prepared to “explore new ideas and ways of working, share and challenge each other's knowledge, work through open-ended problems, navigate relationships [and] learn about themselves" are more likely to experience transformational outcomes. As they engage in professional communities of practice, educators have opportunities to network, thereby helping to reduce isolation, and encouraging revitalisation and innovation [2].

In terms of achieving transformational outcomes the professional dimension of the framework is evidenced at the cause, process, and effective levels of change. Change was caused, in part, by the need to re-envisage teaching and learning to align with 21 st century and not 20 th century requirements. The result at a professional level was that being innovative resulted in a form of professional reframing - a new way of being, knowing and doing at a professional level. In keeping with [36], "becoming" transformational educators was possible by casting a critical lens over learning, teaching and pedagogy [30].

\subsection{Shifting Identities}

The change process at Unitec saw the introduction of new terminology in relation to roles and responsibilities. The title Lecturer was no longer relevant, with roles being renamed and redefined as "course facilitators" and "course leaders". Participant 3 explains that "I was being asked to move from my identity as a lecturer, to become a 'learning facilitator'". Furthermore, Participant 1 talks about the effect of the experience in terms of entering a new territory of evolving roles as the change process got underway. At times roles were ambiguous - an unfamiliar situation within the traditional academic world: "I have the real making of a living job in that my role has shifted and changed as needs have dictated. At times my role has been clear and at other times it has felt like I have been navigating treacle as I manoeuvre through this evolving space". Furthermore Participant 3 likens her experience and role in this newly emerging environment to "Employing a rhizomatic approach...in an environment that is so new it felt unstable as it constantly grows, expands, innovates, and evolves". In these reflective narratives the participants highlight the need to be more agile in professional ways of working to enable timely responses to development needs. 
According to Mezirow [30], transformation can be epochal, involving dramatic or major changes, and/or incremental, involving objective (task oriented) or subjective (self-reflective) reframing. In the professional domain the experience of change led us to question our actions at both levels. For example Participant 1 talks about feeling the moment when transformation became more transparent: "The sense of being dangerously progressive was one that really kicked in when we began the actual delivery of our new blended-flipped courses....in relation to challenging their [student] preconceptions as to how tertiary education happened". Participant 3 talks about the strain of balancing perceived contradictory needs she explained: "On the one hand I wanted to teach responsively and reach out to Māori students to engage them in relation-based, face-to-face learning encounters that I knew they were familiar with. On the other hand I had an obligation to the methodological approach that was being trialled".

\subsection{Embracing Dissonance}

The development process was highly collaborative in nature. This in itself was transformative at multiple levels. No longer were academics working in isolation; rather teams of writers and developers needed to liaise closely with multiple stakeholders. Participant 1 referred to a need for "a meeting of minds". Participant 2 talks about the overall process as involving "a collaborative writing and curriculum editing approach". Furthermore, Participant 1 identified the need for transparency "to enhance curriculum design, editing and the building of the blended-flipped courses". The collaborative process enabled team members to get to know and understand different needs and expectations, thereby helping to ensure effective professional support [37]. Participant 2 explains that she "felt the process was going to offer some great opportunities for hands-on professional development through writers being immersed in the process, while being mentored and guided by a Curriculum Editor". This also led to team members supporting each other professionally as they faced challenges in a more collegial and "open" space.

Taking risks in this collaborative environment was the precursor to new ways of professional knowing. Being on the "learning edge" and in a state of readiness for transformation was a balance between comfort and challenge akin to being within a Vygotskian Zone of Proximal Development [38]. For example, Participant 3 talks about navigating the new space in which she found herself as "struggling to find and know the new terrain being created as a teacher". In a broader sense the change process was about developing ways of being and becoming. For some, it was not about being innovative; rather it was about rejecting the "new" and maintaining a state of being. Participant 2 reflects that "there were some writers that did not appear to "take" to the approach and...didn't seem open to shifting their practice....as well as others who felt quite vulnerable and found the collaborative writing process threatening".

Being on the learning edge required momentum and keen focus because all too easily new ways of being can be lost and old ways resorted to. For example, Participant 1 explains that "using scenarios, case studies, problem solving that are embedded within real world issues and events...can feel like a radical and dangerously progressive undertaking with a tendency to revert back to memory testing continually raising its (ugly) head". Furthermore, differences between courses, which took a process focus over those that were content-driven, posed a challenge to maintaining the rationale and cause for the changes in learning and teaching in the first place. Participant 1 reflects that "when content becomes the driver for course design there is tendency to think of density and ... the focus can turn to giving 
students the required information (knowledge) as opposed to inviting students to explore and engaging them more with the process of learning. A challenge then becomes one of how we, as course designers and developers, ... [keep] co-constructivism at the heart of what we are designing and not ... [slip] into didactic habits".

\section{Political}

The word political has a wide range of connotations. In this paper we use a broad definition which relates back to the original Greek politikos, and carries aspects of the influence of people on global, civic, cultural or individual levels, as well as inferring the more commonly recognised notions of governance [39] (n.d). When the wider inference of "political" is used the political dimension captures the wider notions of the why of education - for society, educators, education institutions, and governance related organisations [40]. In this paper the political dimension attends more to the internal culture of the institution than the wider socio-political context of education within Aotearoa, New Zealand.

At the institutional level, educational change as a form of organisational change is acknowledged as being best understood within unique contextual parameters [41]. This means that despite wider socio-political directives a "one size fits all" approach is no more suitable to be applied to change processes than it is to education. Change occurs within the unique human systems that constitutes the climate and culture of an organisation, its internal political context, and as such generalisation from one context to another is likely to be problematic. (Climate and culture are acknowledged as different, culture being the system of shared values and beliefs that guide behaviour in an organisation; climate being how members of the organisation experience the culture-[42]).

It has been identified $[43,44]$ that how an organisation approaches the following dimensions is significant in terms of the shaping of organisational behaviour and internal political environments:

- autonomy

- trust

- cohesiveness

- support

- recognition

- innovation

- fairness

Consideration of these dimensions is significant to the discussion of the change process within this section of the paper.

\subsection{Benefits of Autonomy}

The change process permitted us to be creative and innovative in how we met the institutional objectives. While the "what" was directed by the executive team the "how" was more open to the actual development team to decide. We had to meet the demands of numerous stakeholders; however, the change process enabled us to draw on new approaches in writing and development, as well as learning and teaching. Participant 1 talks about the challenges of responding to stakeholders but also meeting the wider objectives of the change process "to ensure that, in the design process, the course was free of any 
particular discipline perspective; ensuring a generic 'vanilla' course that could provide a foundation for multiple disciplines within the faculty".

\subsection{Influence of Previous Change}

The dimension of trust was significant but was hampered by past experiences of change within the institution. For instance Participant 1 reflected that a "recent history of change within the institution seemed to have brought with it an air of distrust and scepticism". Furthermore as identified by Participant 3: "if a new teaching and learning paradigm is introduced at a time when an organisation is undergoing major financial restructuring, and that includes redefining the viability of programmes, the potential of a new paradigm and the benefits to learners are in danger of being overshadowed by an ensuing culture of uncertainty and scepticism". Understanding the "why" of change was as important as the "how" as this was arguably the most significant change that the institution had seen in terms of direct impact on professional practice.

\subsection{The Double Edged Sword: Cohesiveness}

To ensure cohesiveness, there was a need to ensure consistency, to hold firm to the ideology underlying the developments, and to navigate the practical implications of the process at hand. We needed to be working to the same goals, using the same methodologies and aiming for the same outcomes, but this can be difficult when leaders within the project were facing contradictory pressures. Cardno [45] (p. 33) explains that "whichever way the leader acts there is likely to be an uncomfortable situation for one of the parties involved". This is outlined in part by Participant 2 who identifies that "within the organisation, there is an uneasy dichotomy between the support for the initiative from senior management, and the sense of urgency to roll out the courses to students to see a return on investment as soon as possible. While this is totally understandable, it also means that I feel torn between ensuring a really rigorous quality assurance and piloting process, and meeting the expectations to deliver". Indeed it became clear that internal systems of communication and relationships could be active in either supporting or undermining the change process, at times with varying responses from the same person on differing occasions. The need for hard decision-making and leadership capacity to accordingly manage dilemmas played a significant part in the confidence with, and smooth running of, the change process.

\subsection{Misalignments between Support Requirements}

Whilst support was evidenced through the ongoing, hard fought for, resourcing there was a misalignment between understanding in terms of the estimated and real resourcing needs. Participant 2 identifies feelings of "frustration" due to the "gap in understanding between how much resource was estimated for an initiative of this scope, and how much is actually required". She also describes the risks: "Personally I get a sense of a job done not quite well enough, of not quite enough support offered, of writers who are writing under incredible pressure, of curriculum editors who would like the space to develop professional relationships further, and of eLearning designers and builders working flat out". 


\subsection{Recognition}

Change can be a risky business. Such risks included a wider-institutional fear for job security, and surviving the negativity expressed by those resistant to the progressive changes, while also trying to develop new workload models and approaches. For example Participant 1 reflected: "at this time the most challenging aspects were managing time (as I was only 0.2 for course writing) and also negativity from colleagues both within and outside of my own department". Nevertheless, Participant 2 reflected that: "There is still a great enthusiasm for the project and belief that it offers an enhanced learning experience for a wide variety of learners. However, there are a lot of tired faces, and folks for whom working in the evenings and at the weekends means they are spending less time with friends and family". Despite this, Participant 2 also recognised the benefits of undertaking change emerging from complex collaborations, using terms such as "enthused" and "inspired".

\subsection{Equity Issues}

The dimension of fairness was challenged by new ways of working and the impact on new conceptions of workload, time, roles and titles. In addition, Participant 3 observed that she had concerns about the issue of resourcing and its impact on the student experience, indicating: "the staffing was not conducive to the level of support the literature was telling me would ensure the best outcome for student experience and success". Participant 2 relates that "there are things underway to help address workload issues and to bring on additional team members, but, as noted above, they are hampered by wider institutional procedures...and, quite possibly, a sense of mistrust of the change that is underway".

\subsection{Innovation and the "Slow laborious Beast"}

Within Te Kura Whānui we experienced rapid, radical, cultural and climate shifts as a result of the change process, which exacerbated a sense of the institution being akin to a slow and laborious beast. For instance Participant 2 reflected that "Te Kura Whānui—as a small "centre" that is responsive, has a relatively flat organic structure, and a focus on innovation - is struggling within the larger overall organisation's existing structures and formal procedures. These structures and procedures are essential for the organisation as a whole, but seem to be contradictory to supporting and enabling innovation". Here we were trying to be adaptable, flexible and agile when the mechanisms and structures we were working within were slow, onerous and out of sync with our need to be agile.

The realisation was that existing systems and structures were no longer compatible with the new ways of doing - as Participant 1 described "the actual management of the changes led to a rising of the pragmatists as we battled with the day to day logistics of working in ways which challenged the existing systems and processes". These tensions led to a need to be mindful of how we moved forward so that we did not lose the ideology and philosophy behind making changes. It was like teaching elephants to dance. A sentiment further highlighted by Participant 2 when she reflected that: "Organisational knowledge seems to undermine the dynamic capabilities required for an iterative cycle of rapid innovation, implementation, evaluation, and application of learnings to subsequent learnings". 


\section{Taking a Moment: Discussion}

Educators are part of a variety of systems and communities, with a range of responsibilities; at all points they are influenced by their personal lives (including aspirations and obligations), as well as professional and political factors that are never frozen in time and are continually changing [46]. While we are aware that change happens, it is challenging to actually "record" it, especially as change occurs across societies, institutions, cultures, and individuals [46]. It has also been observed that there is a tendency to blur the cause, process and effect of change; treating them as one and the same [47]. The impact of this is that while much has been written about change, it has "limited usefulness unless... [it] can be translated into effective action" [46] (n.p).

As a new venture Te Kura Whānui has evolved from an initial concept to a reality.s part of an evolving process, radical ways of working have been trialled, and along with them, new identities have formed. Roles have shifted and changed and morphed as the centre expands and moves into ever new territory. It is the changing roles and working processes which we would argue are most significant in terms of being new, radical and possibly dangerously progressive. Whilst we cannot argue that these changing roles and working processes are unique or even initiated by the experiences within Te Kura Whānui and Unitec, they are significant to the internal context of Unitec and hold wider implications for institution-wide change in relation to not only changing the nature of learning and teaching, but also the changing nature of what it means to be an educator and what is means to be an academic.

In regards to roles, we highlight that the change process has required a willingness and ability to move out of predefined roles, boundaries and time frames and into an ever-evolving and morphing way of working. This dynamic environment has had both benefits and challenges, whereby old slow ways of working were overridden, and highly responsive alternatives implemented.

The major shift to working collaboratively and transparently in the process of course development and delivery meant that academic silos were not the norm (or even the desired). Exposing our own raw thinking to peers as part of the writing process was both enlightening, inspiring and threatening. It also posed a threat to existing perceptions of self as knower of content and pedagogy to meet the new demands of the flipped-blended models of delivery. Notions of being an "expert" were challenged and put under the microscope, and being open to co-construction influenced engagement with students as well as educator attitudes towards their own knowledge and mindsets. Working collaboratively was defined not only by skills and knowledge, but also relationships. Such relationships as described by the participants were hard won but when established could act to inform, support and embrace the change process.

As the innovators and early adopters swiftly became the veterans of the change process they were called onto the act in different roles to lead the ongoing change process. For instance, one of the participants found within a six to eight month period of time her role morphed from that subject matter expert and course writer, to that of course leader and facilitator. Shortly after, she moved into the role of Acting Head of Centre, and finally moved into the role of Curriculum Leader and Developer spanning the wider realms of Te Kura Whānui. These new roles ranged from the more defined to the less defined, with the the positions themselves emerging out of the change process, requiring the participant to continually re-define herself. 
Further challenges included risk taking which could result in ostracisation from colleagues and former peer groups, and facing contradictions in terms of shifting beliefs about learning. Such challenges drew on existing reserves of resilience, which risked depletion when wider change processes and systems could not meet or keep up with the needs arising from the change process. We identified that the staff at Te Kura Whānui were working over and above the norm and its impact was felt outside of the working environment with burnout becoming a real and ongoing concern.

In relation to change being described as either cyclical or transformative, we feel that much of what we have experienced has been transformative on a personal and professional level. Learning and knowing can be equated to that act of drawing, or mark making. When you rub something out - the line (history) almost disappears but there is always a hollow or mark left on the page that impacts the drawing that follows. Sometimes the lines are deeper-made with more force - or we go back and add them again. Currently, we are still rubbing things out and creating new marks. Underpinning the evolving picture are the lines of experience. So despite any temptation to step back we will never be back fully where we were as we cannot unknow what we know and have learned through the process thus far. However, in our experience, while the process for some appears to have been transformative, this is not the case for all involved. Arguably, this initiative has not yet leapt the chasm, and this is probably one of the biggest hurdles we face. Do we have the momentum to go ahead and jump the chasm to reach the other side-a new way of being, knowing and doing in learning and teaching, which with time, can become business as usual? Or are we wanting to turn around, go back and take another run up?

Transformative change is often uncomfortable, disruptive, holistic, collaborative, happens at all levels, and is irreversible. We have suggested that innovation does not happen without tension and indeed it is tension that actually provides some of the energy that can drive innovative. In being innovative the newness is about critical engagement which, by its very nature, causes dissonance. So coping with being innovative is not about removing the tensions, but rather about being consciously aware and mindful of them to ensure that the innovation can actually happen. It's about surviving and indeed thriving on the tensions as if they were nutrients feeding the change process. However, these tensions need to be managed so as not to overwhelm the initiative, which can lead to implosion and a reversion back to the original ways of being and doing. Through this process we have have been introduced to new questions to seek answers to: How do we sustain the momentum? When does the progressive move into a space that is no longer perceived as innovative, but rather the norm? In addition, what are the implications when this happens?

\section{Conclusions}

In this paper we have explored, from the perspective of three participants, the cause, effect and process of change - which was perceived by some as new, others as radical and by some as dangerously progressive. What we have represented are the perspectives of three participants only. We have distilled these experiences into discussions that help illustrate the pitfalls of blurring cause, processes, and effects of change, especially in reference to individuals and the institution. Within our own reflective narratives each of these aspects are distinct yet connected, such that they show interrelated parts - and hence are significant for management of the change process. Despite our differences we have found key themes and issues that are significant to making meaningful sense of the process we have been through. 
As a new venture Te Kura Whānui has evolved from an initial concept to a reality and as part of an evolving process of new ways of working, and along with it, new identities have formed. Roles have shifted and changed and morphed as the centre expands and moves into ever new territory. At this stage in the process we are not at an end point. Rather, we are just further along in the process. The aim over the next phases of change within Te Kura Whānui and Unitec is to "emphasize the little things" [48] (p. 133). By doing so we hope to provide an account of the minutiae of "everyday events that constitute the practical establishment of" [49] (p. 590) an initiative adopting a flipped, blended, and interdisciplinary approach in one "remote corner of the universe" [50] (p. 1). We feel that this level of detail might help identify the nuances that may otherwise be missed, and yet that can fundamentally influence the success, or otherwise, of an initiative. In the next stage we will seek to answer the following questions raised as a consequence of the analysis and discussion of the reflective narratives:

1. How can an educational institution meet the heavy demands of a transformational change, working with innovators and early adopters, without burnout?

2. Is there more than one kind of innovator? What are associated implications?

3. How can educational institutions become more agile and flexible in their pursuit of change so that they stay current and even ahead of the game?

4. How can "time" be better understood and responded to within the change process at the multiple levels of the personal, professional and political?

The paper illustrates that we did some things that resulted in negative outcomes. However, the approach we used means that we have learned along the way and have been able to apply these learnings. In addition, we are seeing some really positive outcomes for students, and this is one area of research we would like to undertake in the near future.

\section{Author Contributions}

Contributions to this paper are shared equally by all authors. All authors contributed in providing reflective accounts which were then analysed and cross analysed by all authors. All authors participated equally in the writing of the paper.

\section{Conflicts of Interest}

The authors declare no conflict of interest.

\section{References}

1. McNiff, J.; Whitehead, J. All You Need to Know about Action Research, 2nd ed.; Sage: Los Angeles, CA, USA, 2011.

2. Owen, H.; Dunmill, M. The Long Journey: Developing a model of PLD for the future. Aust. J. Teach. Educ. 2014, 39, doi:10.14221/ajte.2014v39n1.9.

3. Toynbee, A. A Study of History: Abridgement of Volumes I to VI; Oxford University Press: Oxford, UK, 1947.

4. Wallace, F. Culture and Personality; Random House: New York, NY, USA, 1970. 
5. Souto-Otero, M.; Ulicna, D.; Schaepkens, L.; Bognar, V. Study on the Impact of Non-Formal Education in Youth Organisations on Young People's Employability; European Youth Forum: Brussels, Belgium, 2013.

6. Tertiary Education Commission. Statement of Intent 2013/13-2014/15; Tertiary Education Commission: Wellington, New Zealand, 2012.

7. Welman, J.; Kruger, S. Research Methodology for the Business and Administrative Science; International Thompson: Johannesburg, South Africa, 1999.

8. Schutz, A. The Phenomenology of the Social World; Northwestern University Press: Evanston, IL, USA, 1967.

9. Griffiths, M. Using personal narrative and other stories in educational research: Issues of validity and truthfulness. In Proceedings of the First International Conference on Educational Research for Development, Addis Ababa University, Addis Ababa, Ethiopia, 13-15 May 2009. Available online: http://www.research.ed.ac.uk/portal/files/15324289/Using_personal_narrative_and_other_ stories_in_educational_research.pdf(accessed on 25 January 2014).

10. Fromm, E. To Have or to Be? Jonathon Cape: London, UK, 1978.

11. Samaras, A.P. Self-Study Teacher Research: Improving Your Practice through Collaborative Inquiry; SAGE Publications: Thousand Oaks, CA, USA, 2011.

12. Palmer, P.J. The Courage to Teach: Exploring the Inner Landscape of a Teacher's Life, 10th anniversary ed.; Jossey-Bass: San Francisco, CA, USA, 2007.

13. Garrison, R.; Vaughan, N. Blended Learning and Course Redesign in Higher Education: Assessing the Role of Teaching Presence from the Learner Perspective. 2007. Available online: http://www.ucalgary.ca/ (accessed on 20 November 2014).

14. Zemsky, R.; Massy, W. Thwarted Innovation: What Happened to E-Learning and Why. 2004. Available online: http://goo.gl/xa6fKR (accessed on 7 December 2007).

15. Heinze, A.; Proctor, C. Reflections on the Use of Blended Learning. Proceedings of the Education in a Changing Environment, University of Salford, Manchester, UK, 13-14 September 2004. Available online: http://usir.salford.ac.uk/1658/1/4247745025H_CP_-_paper9_5.pdf (accessed on 5 December 2014).

16. Honeycutt, B.; Garrett, J. The Flipped Approach to a Learner-Centered Class; Magna Publications: Madison, WI, USA, 2013.

17. Bonk, C.; Cummings, J. A dozen recommendations for placing the student at the center of Web-based learning. Educ. Med. Int. 1998, 35, 82-89.

18. Unitec Institute of Technology. Faculty of Social and Health Sciences: Te Kura Whānui Centre for Interdisciplinary Scholarship; Unitec Institute of Technology: Auckland, New Zealand, 2014.

19. Owen, H.; Ayling, D.; Flagg, E. From basic participation to transformation: Immersive virtual professional development. In Synergic Integration of Formal and Informal E-Learning Environments for Adult Lifelong Learners; Leone, S., Ed.; Information Science Reference: Hershey, PA, USA, 2013; pp. 47-74.

20. Bolstad, R. Taking a "Future Focus" in Education-What Does It Mean? NZCER Press: Wellington, New Zealand, 2011.

21. Austin, A.E. Challenges and visions for higher education in a complex world: Commentary on Barnett and Barrie. High. Educ. Res. Dev. 2012, 31, 57-64. 
22. Cranefield, J.; Yoong, P.; Huff, S. Driving change through online brokering practices in an online community ecosystem. In Proceedings of the PACIS, Queensland University of Technology, Brisbane, Australia, 7-11 July 2011. Available online: http://aisel.aisnet.org/pacis2011/51/ (accessed on 12 January 2015).

23. Carter, K.; Doyle, W. Teachers' knowledge structures and comprehension processes. In Research Perspectives on the Graduate Preparation of Teachers; Woolfolk, A., Ed.; Prentice Hall: Englewood Cliffs, NJ, USA, 1987; pp. 51-68.

24. Loughran, J. Developing a Pedagogy of Teacher Education: Understanding Teaching and Learning about Teaching; Routledge: London, UK, 2006.

25. Rogers, E. Diffusion of Innovations; Free Press of Glence: New York, NY, USA, 1962.

26. Moore, G.A. Crossing the Chasm: Marketing and Selling Disruptive Products to Mainstream Customers; HarperBusiness Essentials: New York, NY, USA, 2002.

27. Gladwell, M. The Tipping Point: How Little Things can Make a Big Difference; Back Bay Books: Boston, MA, USA, 2002.

28. Bonk, C.; Cummings, J.; Hara, N.; Fischler, R.; Lee, S. A ten level web integration continuum for Higher Education. In Instructional and Cognitive Impacts of Web-Based Education; Abbey, B., Ed.; Idea Group Publisher: Hershey, PA, USA, 2000; pp. 56-77.

29. Dunmill, M. Secondary Music Teachers Content Knowledge and Skill Bases: Implications for Teacher Education. Master's Thesis, University of Canterbury, Christchurch, New Zealand, 1999.

30. Mezirow, J. Transformative learning theory. In Transformative Learning in Practice: Insights from Community, Workplace, and Higher Education; Mezirow, J., Taylor, E., Eds.; Jossey-Bass: San Francisco, CA, USA, 2009; pp. 18-31.

31. Owen, H.; Allardice, R. Managing the implementation of blended E-learning initiatives with the unconverted in a climate of institutionally driven change. In Engaging Hybrid and Blended Learning in Higher Education; Westover, J.H., Westover, J.P., Eds.; Common Ground Publishing: Champaign, IL, USA, 2014; pp. 50-68.

32. Campbell, M. Learning as Submission? [Blog post]. Available online: http://goo.gl/bYpTNH (accessed on 20 November 2014).

33. Dron, J. Social Velcro. Available online: http://goo.gl/AmzcCt (accessed on 29 December 2010).

34. Bull, A.; Gilbert, J. Swimming out of Our Depth? Leading Learning in 21st Century Schools; NCER: Wellington, New Zealand, 2012.

35. Eraut, M. Learning from other people in the workplace. In Pedagogy and Practice-Culture and Identities; Hall, K., Murphy, P., Soler, J., Eds.; SAGE: London, UK, 2008; pp. 40-57.

36. Bolstad, R.; Gilbert, J.; McDowall, S.; New Zealand Ministry of Education. Supporting Future-Oriented Learning \& Teaching a New Zealand Perspective; Ministry of Education: Wellington, New Zealand, 2012.

37. Donovan, S.; Bransford, J.; Pellegrino, J.W. How People Learn: Ridging Research and Practice; National Academy Press: Washington, DC, USA, 1999.

38. Vygotsky, L. Mind in Society: The Development of Higher Psychological Processes; Harvard University Press: Cambridge, MA, USA, 1978.

39. Liddell, H.; Scott, R. Perseus Digital Library. Available online http://goo.gl/iRdGfD (accessed on 12 September 2014). 
40. Owen, H.; Dunmill, M. “The best PLD I've ever had": Reconceptualising professional learning and development. Prof. Dev. Educ. 2015, in Press.

41. Harris, A. School Improvement: What's in It for Schools? Routledge/Falmer: London, UK, 2002.

42. McLaughlin, J. Organizational Climate: Definition, Factors \& Impacts on Culture. Available online: http://goo.gl/FxKP0i (accessed on 14 January 2015).

43. McMurray, D. Exploring the Concept of "Community" in Online Settings. Paper Presented at the Third Pan-Commonwealth Forum on Open Learning, Dunedin, New Zealand, 4-8 July 2004. Available online: http://www.col.org/pcf3/Papers/PDFs/McMurray_DW.pdf (accessed on 20 September 2013).

44. Moran, E.T.; Volkwein, J. The cultural approach to the formation of organizational climate. Hum. Relat. 1992, 45, 19-47.

45. Cardno, C. Leadership learning - The praxis of dilemma management. Indep. Sch. Educ. Assoc. 2007, 35, 33-50.

46. London, S. Understanding Change: How It Happens and How to Make It Happen. 1996. Available online: http://www.scottlondon.com/reports/change.html (accessed on 20 December 2014).

47. Kuhn, T.S. The Structure of Scientific Revolutions, 3rd ed.; University of Chicago Press: Chicago, IL, USA, 1996.

48. Flyvbjerg, B. Making Social Science Matter Why Social Inquiry Fails and How It can Succeed Again; Cambridge University Press: Oxford, UK, 2001.

49. O’Neill, J.; Bourke, R.; Kearney, A. Discourses of inclusion in initial teacher education: Unravelling a New Zealand "number eight wire" knot. Teach. Teach. Educ. 2009, 25, 588-593.

50. Flyvbjerg, B. Rationality and Power: Democracy in Practice; University of Chicago Press: Chicago, IL, USA, 1998.

(C) 2015 by the authors; licensee MDPI, Basel, Switzerland. This article is an open access article distributed under the terms and conditions of the Creative Commons Attribution license (http://creativecommons.org/licenses/by/4.0/). 